\title{
Multimedia Materials for Chemical Engineering: Module Development and Lessons Learned
}

\author{
SUSAN M. MONTGOMERY
}

Chemical Engineering Department, University of Michigan, Ann Arbor, Michigan 48109

\begin{abstract}
In this article we summarize the multimedia materials for chemical engineering instruction developed in our laboratory during the last 3 years. We also share what we have learned about the presentation of materials and the development process itself. (C) 1996 John Wiley \& Sons, Inc.
\end{abstract}

\section{INTRODUCTION}

The Multimedia Education Laboratory of the Chemical Engineering Department at the University of Michigan was founded to develop multimediabased educational materials that integrates exposure to chemical engineering processes and helps students understand difficult concepts. Other laboratory activities include assessments of the effectiveness of the developed material in improving chemical engineering education by reaching a variety of learning styles and levels of pedagogic objectives, and also to conduct research to discern student learning preferences in computer-based educational materials. Felder's learning styles model [1] classifies learners along the five dimensions shown in Table 1. A typical engineering course focuses on theory (intuitive), is typically presented in lecture mode (verbal), presents consequences as resulting from underlying principles (deductive), is passive (reflective), and is presented linearly (sequential).

Computer Applications in Engineering Education, Vol. 4(4) 297-305 (1996)

(c) 1996 John Wiley \& Sons, Inc. $\quad$ CCC 1061-3773/96/040297-09
One research question that we have begun to explore is whether multimedia materials could fill in the learning gaps - that is, address the needs of sensing, visual, inductive, active, and global learners. This article summarizes the software we have developed since our inception in 1993, the lessons we have learned regarding module development and learning style preferences, and our plans for the near future.

\section{THE MULTIMEDIA EDUCATION LABORATORY}

The laboratory consists of one PC computer running Windows and six Macintosh computers for software development, an image scanner, digital camera, videocamera, TV and VCR, laser printers, and a CDROM burner. The modules are developed using Macromedia's Authorware authoring package [2], which allows us to develop on the Macintosh and port to Windows. Spreadsheet simulations are constructed using Microsoft Excel [3], graphics are designed in Adobe Photoshop [4], and we are starting to experiment with Ray Dream Studio [5] tools for more advanced graphical capability. 
Table 1 Felder's Learning Style Dimensions [1]

\begin{tabular}{llr}
\hline Dimension & \multicolumn{1}{c}{ Range } & \multicolumn{1}{c}{ Comments } \\
\hline Perception & Sensing/intuitive & $\begin{array}{c}\text { Sensors prefer data and facts; intuitors prefer theories } \\
\text { and interpretations of factual information. } \\
\text { Visual learners prefer charts, diagrams and pictures, } \\
\text { while verbal learners prefer the spoken or written } \\
\text { word. }\end{array}$ \\
Organization & Inductive/deductive & $\begin{array}{c}\text { Inductive learners prefer to infer principles from facts } \\
\text { and observations; deductive learners deduce } \\
\text { consequences from underlying principles. }\end{array}$ \\
Processing & Active/reflective & $\begin{array}{c}\text { Active learners learn best by doing something } \\
\text { physical with the information, while reflective } \\
\text { learners do the processing in their heads. }\end{array}$ \\
Understanding & Sequential/global & $\begin{array}{c}\text { Sequential learners make linear connections between } \\
\text { individual steps easily; global learners require the } \\
\text { big picture before individual pieces fall into place. }\end{array}$ \\
\hline
\end{tabular}

The development team consists primarily of undergraduate chemical engineering students. In the 3 years of its existence we have also had two chemical engineering masters students serving as developers, and a number of first-year and sophomore students assisted in the development. Most of the development work takes place during the summer, with students working part time during the school year to finish up and update modules as in-class testing takes place. The modules we have developed can be divided into five topics: Introductory Chemical Engineering, Undergraduate Laboratory, Applications of Chemical Engineering in Biological Systems, Chemical Engineering Equipment, and Learning Style Tools.

\section{INTRODUCTORY CHEMICAL ENGINEERING MODULES}

As the instructor for the Material and Energy Balances course for the past 3 years, I had a natural interest in focusing on this course. The modules developed for this course and student reactions to the modules are presented below.

- Pressure and temperature: This module exposes students to the concepts and types of equipment used to measure pressure and temperature. The module includes images from industrial resources showing the equipment in action, as well as questions regarding unit conversions and hydrostatic pressure (Fig. 1). Students appreciated seeing the equipment, but requested additional interaction to practice unit conversions.
- Phase equilibria: This interactive module helps students understand single and multicomponent phase equilibria. The module interactions integrate videoclips of demonstrations and simple experiments, as well as of industrial applications (Fig. 2). In-class testing showed that exposure to the equipment was helpful to the students in that it provided a motivation to learn about multiphase systems.

- Psychrometric charts: Students often have a difficult time mastering the reading of psychrometric charts. We developed a tutorial to provide students with practice reading these charts and predicting the results of a given process using the chart. It includes a review section and a quiz section (Fig. 3). This module will be class tested in Fall 1996.

- Mass balances on phosphate-coating system:

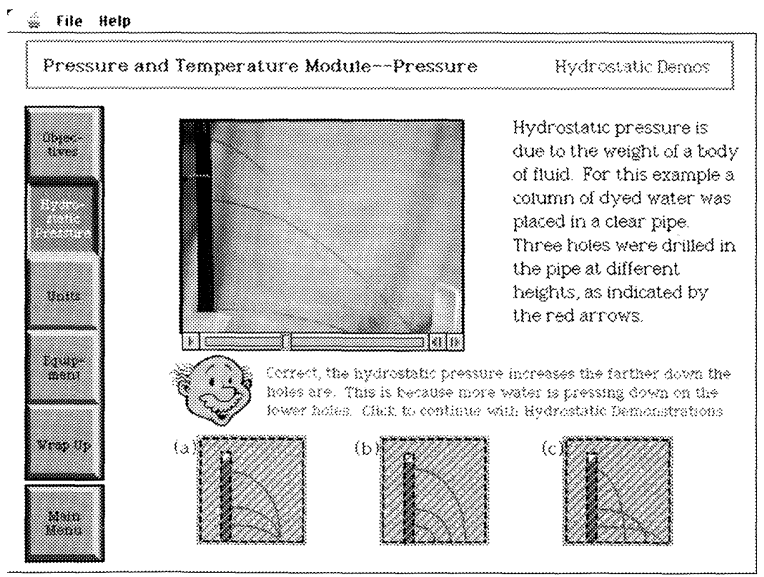

Figure 1 Demonstration of hydrostatic pressure, pressure, and temperature module. 


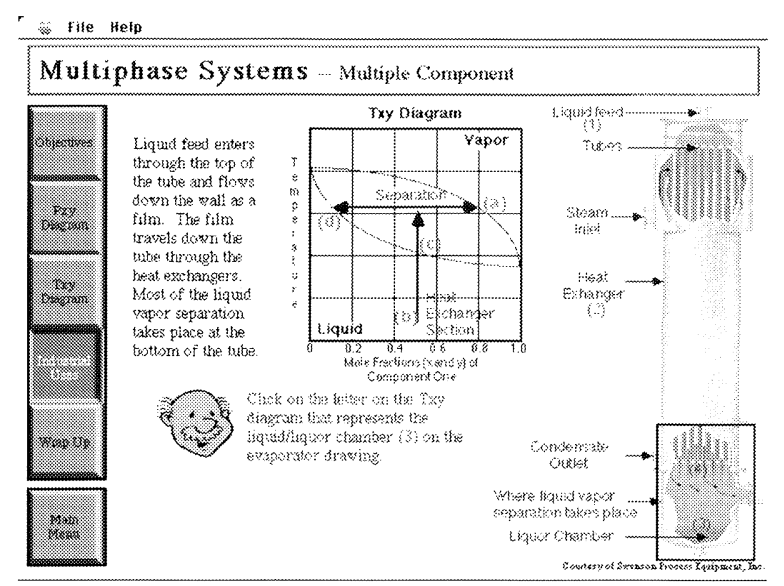

Figure 2 Comprehension exercise, multiphase systems.

This multimedia tour (Fig. 4) is used as part of an open-ended project in which students generate the flowsheet of the phosphate-coating system at Ford Motor Company's Wixom, Michigan, plant, then suggest modifications to minimize the amount of waste generated. This open-ended problem, which was based on the experience of one of our department's students as an intern at Ford through the Environmental Protection Agency's National Pollution Prevention Center for Higher Education, exposes students to the type of challenges they will face in industry. While the students were frustrated at first at the magnitude of this assignment and the open-endedness of it, all groups were able to develop a flowsheet of the system, and make intelligent recommendation for waste minimization. This tour has been distributed by NPPC (nppc@umich.edu) to over 50 academic and industrial clients.

- Mass balances on a wastewater treatment plant: This interactive tutorial starts with a tour of Ann Arbor's waste water treatment plant, which explains the operation of various parts of the plant. Students then must solve mass balance problems involving each of the processing steps (Fig. 5). This module will be class tested in Fall 1996.

\section{UNDERGRADUATE LABORATORY MODULES}

The junior-level chemical engineering laboratory is typically the first course in which students make connections between class theories and chemical engineering processes and equipment. However, by the time they reach this course, students have often forgotten the material they learned in previous courses, and fail to see the interrelations between the various courses in the chemical engineering curriculum. These modules were developed to prepare our students to perform experiments in the undergraduate lab, providing them with the industrial context of the experiment and instructing them in the operation of the equipment, to make more valuable use of limited laboratory time.

- Cooling towers: This module supplements the cooling tower experiment. The goal of the cooling tower sessions are to optimize the performance of a cooling tower. The module (Fig. 6 ) includes a tutorial on psychrometric charts (which was adapted and expanded to develop the introductory tutorial described above), a section on mass transfer theory, and real-world examples of industrial cooling towers. Students felt this review helped them to quickly integrate the subject matter from two courses into a single process. This module would also be effective in a mass transfer course.

- Pumps: This module, which could also be used in the fluid mechanics course, supplements the pumping networks experiment. Students must determine the most effective way to arrange three pumps to satisfy various pumping needs. The module includes a tutorial, with interative problems and videoclips, that helps students understand how to use the apparatus (Fig. 7), as well as the objectives of the experiment. Students can also explore system curves and

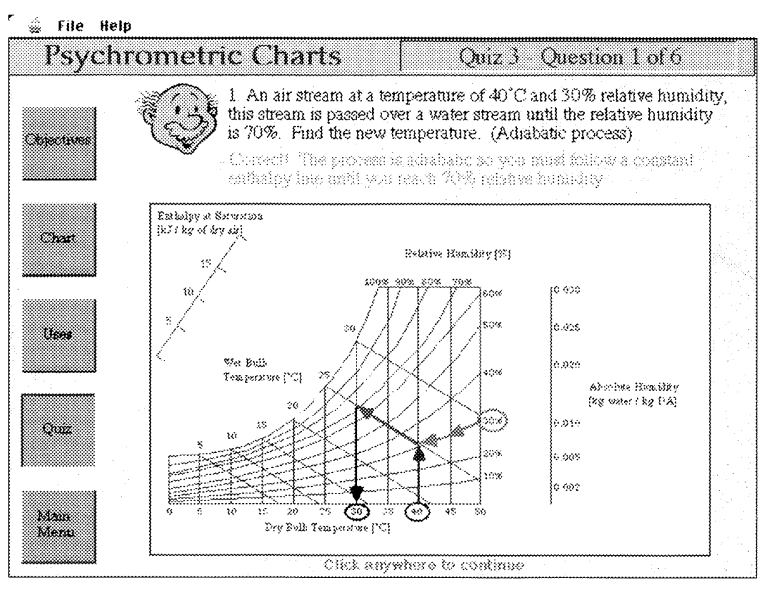

Figure 3 Quiz section, psychrometric chart module. 


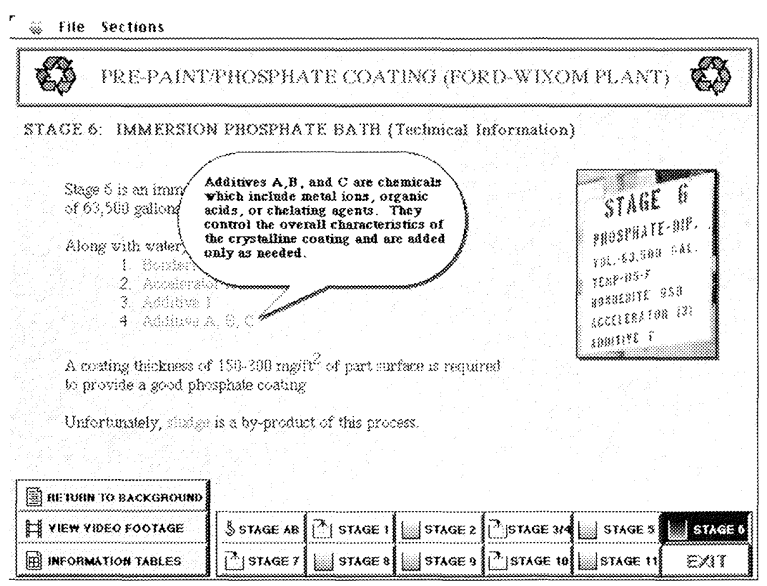

Figure 4 Tour of system, mass balances on phosphatecoating system module.

pumping systems, and learn about how different types of pumps work.

\section{CHEMICAL ENGINEERING IN BIOLOGIC SYSTEMS MODULES}

A significant portion of our undergraduate students are interested in careers related to biology and biotechnology but do not really understand the connections between chemical engineering and biological systems. A team of chemical engineering faculty, including the author, Jennifer Linderman, David Mooney, Scott Fogler, Henry Wang, and Mark Burns, led the development of multimedia materials for the core chemical engineering courses that will provide a biologic context to the chemical engineering material. So far three modules have been developed, described below.

- Adsorption separation: This tutorial focuses on applications of affinity chromatography in biotechnology. The general equations for adsorption in a column are derived and a chromatography column simulator (Fig. 8) can be used to explore the role of various parameters, such as adsorbent diameter, length of the solumn, maximum solute concentration on the solid, adsorption binding constant and flow rate, on column performance.

- Receptors: This module reinforces kinetics concepts in the context of receptor-ligand binding [6]. The module includes an introduction to receptor-ligand systems; a review of the kinetics of binding (Fig. 9); a simulation of re- ceptor-ligand binding as a function of system parameters such as ligand concentration, reaction rate constants, total receptors, and initial number of complexes; and case studies involving signal transduction, and drug delivery.

- Biokinetics and biotechnology: This module focuses on biokinetics as applied to bioremediation and bacteria profile modification. The module includes a review of biokinetics, key requirements for successful bioremediation, simulation of the batch growth of cells based on ongoing bioremediation research [7], transport through porous media, and the use of bacteria for oil recovery (Fig. 10).

Students in the reaction kinetics course tested the receptors and biokinetics modules. Students in a new course developed as part of the same project as the modules, "Engineering Applications in Biological Systems," class-tested these modules. Students appreciated the exposure to biological applications of chemical engineering concepts, the ability to view the material at their own pace, and the use of simulators to explore systems coupled with explorative questions. They did, however, express a desire for additional interactions.

\section{ENCYCLOPEDIA OF CHEMICAL ENGINEERING EQUIPMENT}

Often in engineering education we focus on providing fundamental understanding of theoretical concepts, and we tend to neglect the applications of the theory. We forget that most of our students are not familiar with the processes and equipment they will

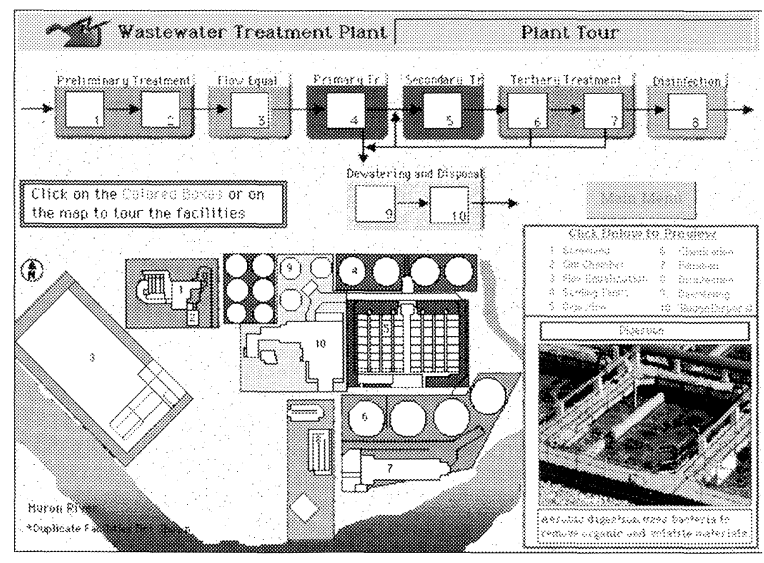

Figure 5 Plant tour menu, mass balances on a wastewater treatment plant. 


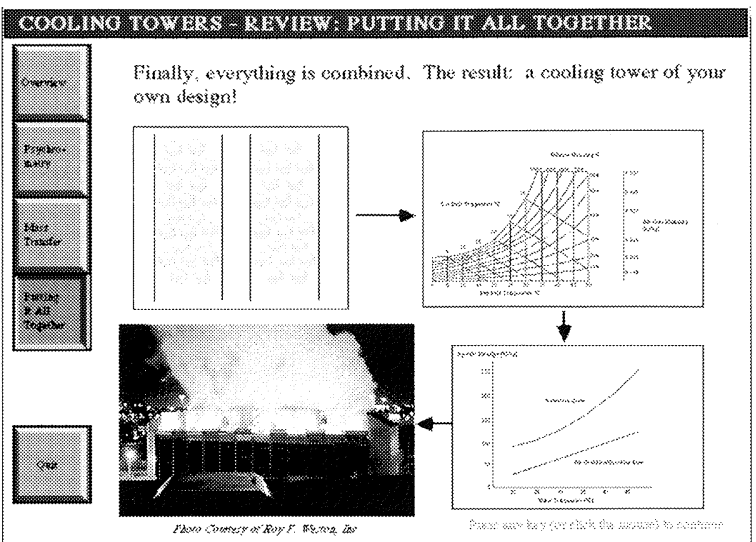

Figure 6 Overview of the design process, cooling tower module.

encounter as professionals. This lack of familiarity can lead to a lack of motivation for the subject matter. In addition, industrial recruiters often bemoan graduating students' lack of familiarity with the components of a chemical engineering plant: These concerns led to the ongoing development of an encyclopedia of chemical engineering manufacturing equipment.

- The Multimedia Encyclopedia of Chemical Engineering Equipment includes technical design information, schematics, pictures, videos, and animations. Sections currently completed include cooling towers (Fig. 11), heat exchangers, pumps, tanks, and distillation columns. Students in the material and energy balances course, for example, were much more enthusiastic about learning basic energy balances after understanding the principles of heat transfer in heat exchangers. In the future we will create links from the modules described earlier to the corresponding equipment's submenu from this encyclopedia.

\section{WHAT WE HAVE LEARNED REGARDING MULTIMEDIA MODULES}

Other developers [8] have shared useful suggestions regarding the technical aspects of multimedia development, such as computer graphics, video, and sound production. The lessons we would like to share concern both enhanced presentation of multimedia educational materials and the management of the development personnel. Most of the modules

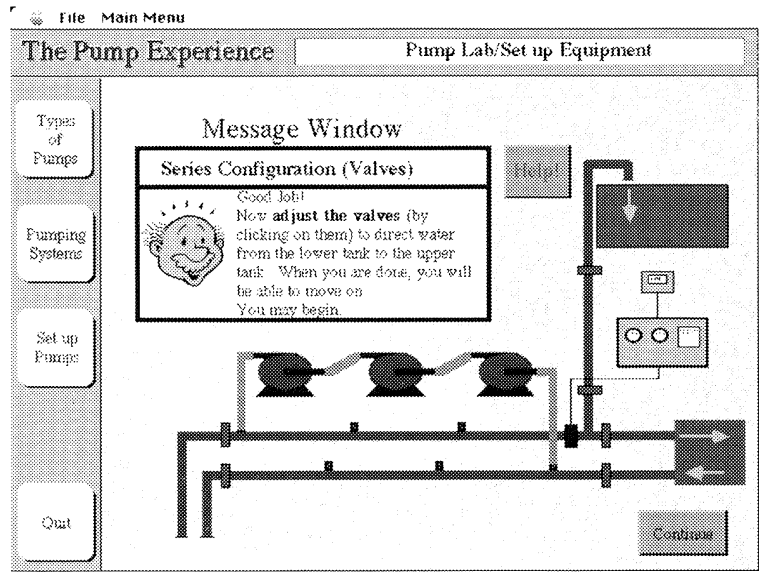

Figure 7 Practice using experimental equipment, pumps module.

described in this article have been class-tested at the University of Michigan, and are currently undergoing testing at other institutions. In addition, some modules were assessed to determine whether they addressed the needs of those learners who do not respond well to traditional teaching methods. To begin these studies we surveyed the students in the introductory course to determine their learning styles. The students were surveyed two more times, once after they used the pressure and temperature module, and again after completing the multiphase systems modules, to determine how effective students felt the modules were in increasing their learning. The results of these tests help us in the ongoing process of module improvement, and as we develop new modules. Preliminary results are presented below.

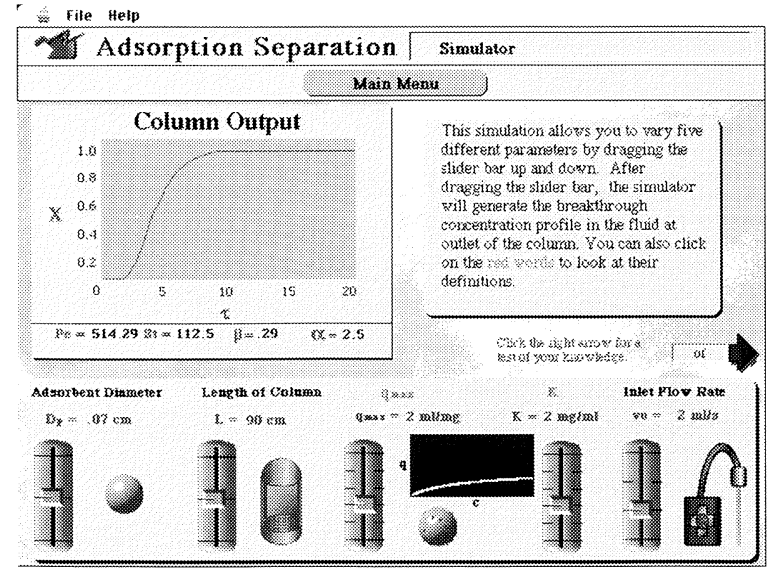

Figure 8 Chromatography column simulator, adsorption module. 


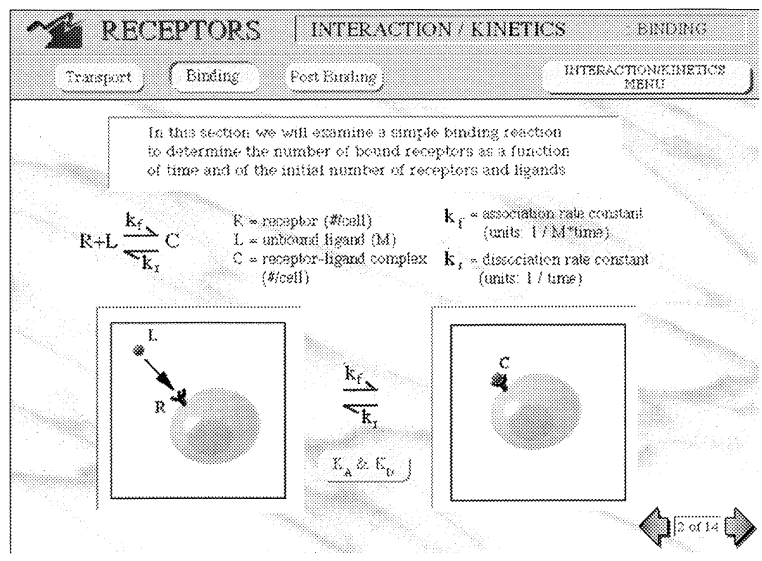

Figure 9 Kinetics of receptor-ligand binding, receptors module.

\section{Content}

- Keep the learners in mind, in particular their learning styles. Multimedia gives educators the opportunity to reach learning styles that are not addressed in a typical classroom setting, as will be discussed in the points below.

- Keep in mind the role of the module components: presentation, assessment, exploration, and analysis [10]. A module that contains only presentation can be greatly enhanced with significant assessment and exploration components.

- Very simple demonstrations can be videotaped and included in the modules, as in the hydrostatic pressure demonstration in Figure 1. Sensing and visual learners expressed a statistically significant preference for the demonstrations

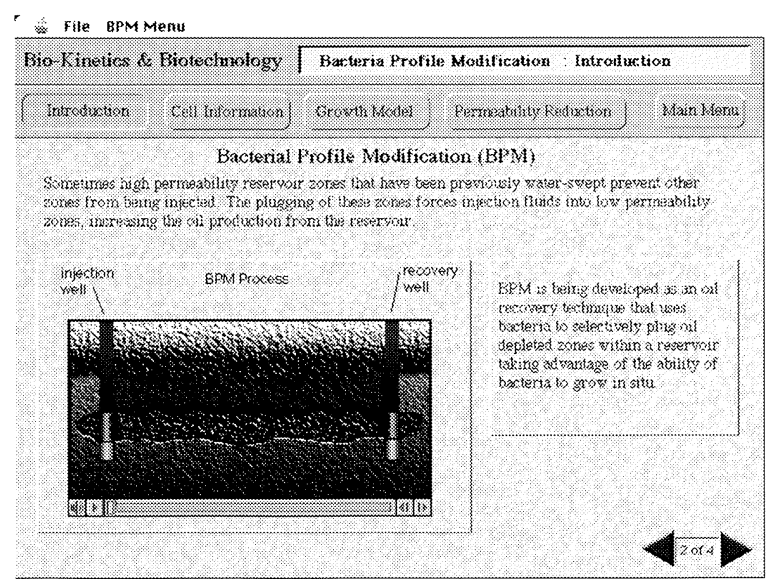

Figure 10 Bacterial profile modification, biokinetics and biotechnology module.

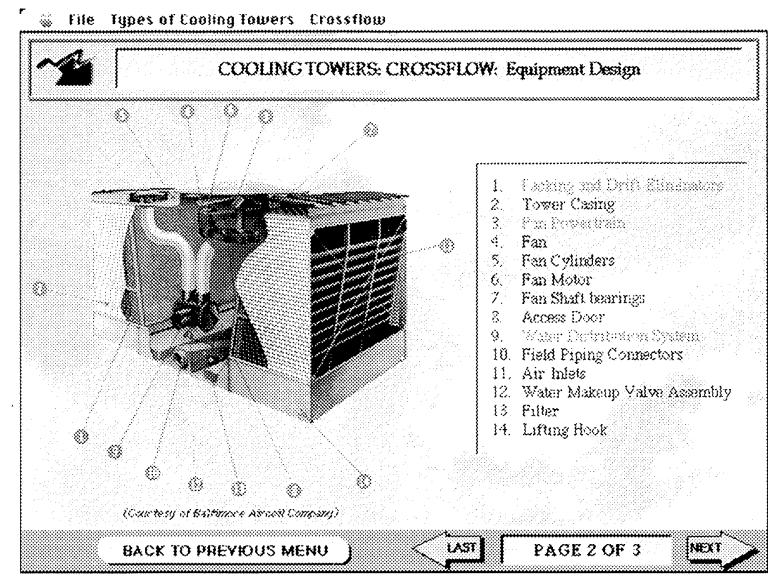

Figure 11 Cooling tower overview, encyclopedia of chemical engineering equipment.

compared to the intuitive and verbal learners, respectively. Sensing learners got a chance to see an application of the concepts being presented, and the visual learners got a reprieve from reading text. No statistically significant differences were noted along the other learning style dimensions. In general students ranked demonstrations highest in terms of their perceived usefulness, as shown in Table 2.

- Interaction is the key. The ability to explore, go at their own pace, and continually test their knowledge are some of the features that render these tools invaluable to students. Figures $1-$ 3 show examples in which students get an opportunity to test their understanding of various chemical engineering concepts, and in the module shown in Figure 7 students can practice setting up experimental equipment before they actually use it [11].

- Show them the real thing. Active, sensing, visual, and sequential learners appreciated seeing pictures and animations of equipment, such as the evaporator in Figure 2. Active learners had something to do and interact with in the mod-

Table 2 Perceived Usefulness of Multimedia Module Components, Pressure/Temperature and Multiphase Module ( 1 = Lowest, 5 = Highest $)$

\begin{tabular}{ll}
\hline Component & Rank \\
\hline Demonstrations & 4.26 \\
Questions & 4.12 \\
Equipment pictures & 4.03 \\
Derivations of equations & 3.82 \\
Movies & 3.46 \\
\hline
\end{tabular}


ule; sensing learners prefer exposure to real situations and visual learners prefer visual information. We had expected the global learners to respond more favorably than the sequential learners to seeing the context for the material presented, but this was not the case.

- Include a review of the derivations of significant equations. Derivations of equations allowed users a chance to review them at their own pace. This is particularly true for sensing learners, who may have had a more difficult time understanding the derivation when first presented in class. In the receptors module, for example, students have an opportunity to review basic kinetics concepts within the context of receptor-ligand binding. An early screen from this development is shown in Figure 9.

- Movies were preferred by active, sensing, and visual learners over their counterparts. This result is similar to the one obtained for the equipment, except that in this case no statistically significant differences were discerned between sequential and global leaners. The low rating of the movies in Table 2 most likely reflects technical difficulties the students encountered in trying to run the movies.

Some other conclusions we have drawn from observations of users include:

- A consistent user interface aids in the navigation. Students should not have to adapt to a changing set of rules from module to module. We have maintained similar interfaces for all modules, particularly those for the same course, as can be seen by the interfaces in Figures 13 for the introductory course, and Figures 8-10 for the "Chemical Engineering in Biological Systems" set of modules.

- Users need to be able to navigate easily through the module. It is too easy to get lost in a module with more than three levels of menus. Check marks in menus to denote sections that have already been explored are beneficial. Perpetually available flowsheets, such as the one shown in Figure 12, are also helpful.

- Users want to be able to page back to previously viewed material, such as in Figures 9 and 10 . They also should be able to move easily between sections, via buttons designating other sections of the module, or through the menus at the top of the screen, and to have an easy way to quit at all times.

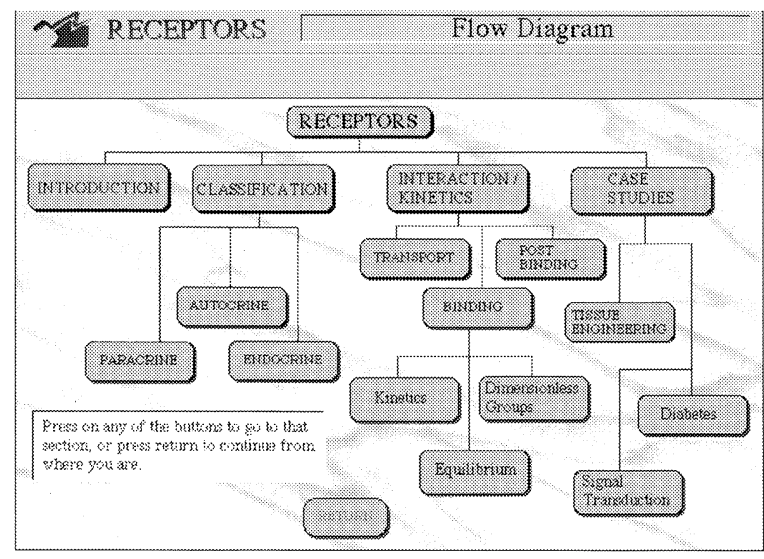

Figure 12 Flowsheet from receptor-ligand binding module.

- Simulations need guidance. Simulations are very useful, in that students can gain an understanding of the effect of various process parameters on a system's performance. However, students using the simulation will often miss some of the effects the professor might want them to learn about, as they might not investigate the appropriate range of variables to make a particular nuance apparent. Asking students pointed questions that guide their exploration can greatly enhance the learning that takes place [12].

- Often students will revisit a module in studying for exams. A feature that we plan to implement is a single-screen summary of the material which students can print out.

\section{Development Process}

In the past 3 years of multimedia development, several key elements of the development process have become evident.

- Undergraduate students can make great developers. We have found them to be very enthusiastic, hard working, and independent. They provide a unique perspective regarding student needs and preferences which is critical to the success of the modules. Students become very dedicated to the project, staying on during the school year to improve their modules [13].

- Technical advice from faculty is critical. While undergraduate students do the bulk of the development work and are a critical component of the development process, it is the faculty 
member who is ultimately responsible for the technical accuracy of the material.

- Continuous review of the modules is important. In our laboratory we have weekly group meetings. Each week is dedicated to one module, and all members of the lab review the module during the week leading to the group meeting. The bulk of the meeting time is dedicated to the pros and cons of the module, and to addressing any concerns and questions that the module's developers might have.

- In addition, outside testing is important if the module is being developed for export, as we have noticed when reviewing material from other universities. One professor's preferred way of presenting material might need to be adapted for external use. Some examples of features that do not travel well include shortcut methods and acronyms that are not appropriately explained in the module, demonstrations performed in class, and references to other courses in the curriculum. Humor also needs to be used with caution.

- Test the materials in the type of machine the target audience will use. Often software developers have top-of-the-line machines, and what runs well on their machines might be painfully slow in the machines available for student use.

- Dedicating one person to graphics can be efficient, so that not every student needs to become a graphic artist. The same suggestion applies to spreadsheet packages if you plan to use them extensively.

- Obtain licenses to use materials from external sources. The university's Technology Management Office drafted a licensing agreement for any graphic obtained from external sources. One of our students maintains all records of licensing for our graphics. For the most part, companies have been amenable to our use of the materials for educational purposes.

The overriding concept to keep in mind when developing multimedia materials is the way in which the materials truly enhance education. Merely copying the coursepack to the computer, as the author has seen done, is useless if one does not take advantage of the opportunities for interaction, self-paced, and personalized learning, animations, graphics, demonstrations, and other features described above.

\section{FUTURE PLANS}

Additional information about the modules can be obtained through our World Wide Web page, at http://www.engin.umich.edu/labs/mel, or by contacting smontgom @umich.edu. During the summer of 1996 we are developing two new modules in the bioproject: One will focus on mass balances, the other on diffusion. During Summer 1997 we will make final changes to all the biomodules and prepare them for distribution through the Computer Aids for Chemical Engineering Education Corporation (cache@uts.cc.utexas.edu). Work on the Material and Energy Balances course modules and the Encyclopedia of Chemical Engineering Equipment continues.

\section{ACKNOWLEDGMENTS}

Many thanks go to the software developers for the various modules: Michael Africa, Eric Green, Susan Maskery, Ken Wong, David Spitzley, Phil Cusick, John Chan, Renee St. Germaine, Edvins Daiga, Jason Arthur, Brad Ruiter, Jason Holmberg, Jim Shimota, Gregg Frohman, Betsy Schornak, Jennifer Barber, Blia Kue, Kim Dillon, and Amjed Al-Zoubi. Thanks also to Michael Neylon, Eric Bonhert, Dan Moon, Darian Ware, Lynn Zwica, and Kevin Dailey for their assistance. The phosphate-coating system was based on a problem developed through the $\mathrm{Na}$ tional Pollution Prevention Center's innovative internship program (nppc@umich.edu); and the assistance of Philip Lawrence of Ford Motor Company in supervising the student and providing the movies of the plant was much appreciated. The willingness of so many companies to allow us to use their visual information have made the Encyclopedia of Chemical Engineering Equipment possible. Seed funding from the University of Michigan's Center for Research on Learning and Teaching and the Office of the Vice-Provost for Academic and Multicultural Affairs was essential in getting us started. The author also gratefully acknowledges National Science Foundation Grant EEC 9420567, which made the development of the modules on biotechnology possible, as well as Grant DUE9555125, which is funding the development of materials for the materials and energy balances course.

\section{REFERENCES}

[1] R. M. Felder, "'Reaching the second tier-learning and teaching styles in college science education,', 
J. Coll. Sci. Teach., Vol. 23, No. 5, 1993, pp. 286290.

[2] Authorware, Macromedia, Inc., 600 Townsend St., San Francisco, CA 94103.

[3] Microsoft Excel, Microsoft Corporation, One Microsoft Way, Redmond, WA 98052-6399

[4] Adobe Photoshop, Adobe Systems, Inc., 1585 Charleston Rd., Mountain View, CA 94039.

[5] Ray Dream Studio, Ray Dream, Inc., 1804 N. Shoreline Blvd., Mountain View, CA 94043.

[6] D. A. Lauffenberger and J. J. Linderman, Receptors: Models for Binding, Trafficking, and Signaling. Oxford University Press, New York, 1993.

[7] R. E. Lappan and H. S. Fogler, "Leuconostoc mesenteroides growth kinetics with application to bacterial profile modification,' Biotech. Bioeng., Vol. 43, 1994, pp. 865-873.

[8] M. F. Iskander, J. Catten, R. Jameson, A. Jones, and A. Balcells, "Development of multimedia modules

\section{BIOGRAPHY}

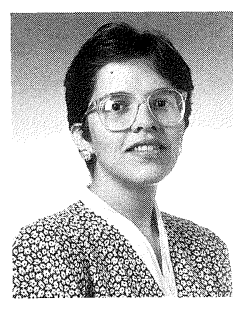

Susan Montgomery is an assistant professor of chemical engineering at the University of Michigan. She received a BSEChE from the University of Michigan in 1984, earned an MA and PhD from Princeton University in 1991, and joined the faculty of chemical engineering at the University of Michigan in 1993. In 1995 she was the recipient of a Dow Outstanding New Faculty Award. Her research interests are in engineering education, particularly learning styles and the use of computers for educational purposes. for education," Comp. Appl. Eng. Educ., Vol. 3, No. 2, 1995, pp. 97-110.

[9] B. S. Soloman, "Inventory of learning styles," North Carolina State University, 1992.

[10] S. M. Montgomery and H. S. Fogler, "Selecting computer-aided instructional software," J. Eng. Educ., Vol. 85, No. 1, 1996, pp. 53-60.

[11] M. F. Iskander, J. C. Catten, R. M. Jameson, A. Rodriguez-Balcells, and A. K. Jones, "Interactive multimedia CD-ROMs for education," Comput. Appl. Eng. Educ., Vol. 4, No. 1, 1996, pp. 51-60.

[12] H. Kuznetsov, "Innovative multimedia instruction and sophisticated problem solving exercise and testing in engineering statics and structural planning," Comput. Appl. Eng. Educ., Vol. 4, No. 1, 1996, pp. 61-66.

[13] S. E. LeBlanc, H. S. Fogler, and S. Montgomery, "Interactive creative problem solving,' Comput. Appl. Eng. Educ., Vol. 4, No. 1, 1996, pp. 35-40. 